10 years ESJ

Special edition

\title{
Coronary Disease Risk in Asymptomatic Patients with Left Ventricular Moderate Dilatation
}

\author{
Zeikidze Solomon, MD, PhD, Asisstant professor \\ David Aghmashenebeli University of Georgia, Georgia \\ Suladze Andro, $M D$ \\ LTD Tbilisi Heart and Vascular Clinic, Georgia \\ Zeikidze Nikolozi, Student \\ Faculty of Medicine Ivane Javakhishvili \\ Tbilisi State University, Tbilisi, Georgia
}

Doi: 10.19044/esj.2021.v17n18p1
Submitted: 02 November 2020
Copyright 2021 Author(s)
Accepted: 02 February 2021
Under Creative Commons BY-NC-ND
Published: 01 June 2021
4.0 OPEN ACCESS

Cite As:

Solomon Z., AndroS. \& Nikolozi Z. (2021). Coronary Disease Risk in Asymptomatic Patients with Left Ventricular Moderate Dilatation. European Scientific Journal, ESJ, 17(18), 1.

https://doi.org/10.19044/esj.2021.v17n18p1

\begin{abstract}
Goal of the Study is to assess the risk of coronary disease of asymptomatic ischemia in patients with left ventricular moderate dilatation. Methods: The work was based on the results of investigation of 185patients with left ventricular moderate dilatation, aged 35-55 years from the "Tbilisi Heart and Vascular Clinic" contingent. Among them, there are 159 men and 26 women. Results: Patients who suffer from left ventricular moderate dilatation and don't expose typical symptom of ischemia possibly are in risk of carrying damaged coronary artery. the LV moderate dilatation of the left ventricle can be used for primary diagnosing of silent ischemia. Sensitivity 0.867(95\%CI:0.806-0.927); Specificity - 0.800(95\%CI:0.703-0.897); Prognostic value of positive results; 0.889(95\%CI:0.832-0.946); Prognostic value of negative results - $0.765(95 \% \mathrm{CI}: 0.664-0.866)$; diagnostic value 0.843(95\%CI:0.791-0.896). Conclusions: In patients with silent ischemia, the coronary disease predictors are: left ventricular moderate dilatation, male gender, dyslipidemia, arterial hypertension, smoking, positive treadmill test, ischemic disease in 1st degree relatives, low tolerance to treadmill test. Thus,
\end{abstract}


we can use the moderate dilatation of the left ventricle for the primary diagnosing of silent ischemia. The test is simple and non-invasive. It is characterized by high sensitivity and specificity and can be used for early diagnosing of silent ischemia and the prevention of cardiac cases.

Keywords: Silent ischemia, Left ventricular moderate dilatation, Asymptomatic patients, coronary artery disease

\section{Introduction}

Cardiovascular diseasesare the most frequent cause of death even in the contemporary world. Often the first symptoms of coronary diseases are catastrophic and are revealed when atherosclerotic process is already developed [Gutermann et al. 2009].

Mortality, caused by cardiovascular diseases ranges from 4 to $42 \%$ in countries of different economic development [Mendis, S., et al. 2011]. Therefore, early stage detection and prevention are especially important. Frequently, the very first manifestation of coronary disease is extremely fatal. In $60-70 \%$ of cases, the coronary artery disease is revealed by myocardial infarction or sudden death. The late stage demonstration of the symptoms may be associated with the sensory mechanism disorder of the heart [Gutermann et al.,2009]. According to the investigation, the stimulator of the ischemic pain of the heart is the lactate. Elevation of its level leads to the activation of pain receptors and the chest pain [Abd El-Aziz, 2015].

Myocardial Ischemia can progress without symptoms. The cases of asymptomatic silent ischemia exceed the symptomatic ischemia cases [Conti, C. R., 2012].The Left ventricular diameter is associated with sudden cardiac death [Narayanan, K. 2014.].

Thus, in silent or "mute" (asymptomatic)stenocardia, the mortality risk increases as far as the condition,when there are serious disorders in the organism and the person cannot feel them, is extremely dangerous. Subsequently, no timely treatment is taken and the danger of serious complications and death increases [Hansson, G. K., 2016].

According to the literature, $35 \%$ of moderate dilatation cases do not demonstrate the trend of development, $24 \%$ can be transformed into dilatational cardiomyopathy. The rest is characterized by non-stable ventricular arrhythmias and poor prognosis [Gigli, M. 2017].

On the basis of practical experience and observation, it turned out that the people, who had moderate dilatation of the left ventricle by ultrasound and never had stenocardial complaints, showed positive or suspicious in stress-test of physical exertion. The question arose: Was there any correlation between these two pathologies? These patients' selective coronagraphy data proved our supposition. It was considered interesting to study the issue extensively and 
deeply in order to answer the above question: does the left ventricular moderate dilatation present the risk of developing heart coronary disease.

The goal of the study is to assess the risk of coronary disease in patients with asymptomatic ischemia of the left ventricular moderate dilatation.

Methods: The work was based on the results of the investigation of 185patients with left ventricular moderate dilatation, All patients aged 35-55 years who were admitted to the "Tbilisi Heart and Vascular Clinic" in 20152018, and meeting the inclusion and exclusion criteria, were examined.

Among them, there are 159 men and 26 women. All of them underwent selective coronagraphy. The patients were distributed according to the coronagraphy data. The first group consisted of patients with coronary stenosis and the second group consisted of patients with intact coronaries.

Inclusion Criteria: Patients with asymptomatic ischemia, informed consent for participation in the study

Exclusion Criteria: Patients with typical stenocardial complaints, dilatative cardiopathy, congenital and acquired heart defects, suffered myocardial infarction, suffered myocarditis.

Methods of Investigation: Clinical, clinical-laboratory and biochemical (lipid spectrum, coagulogram, glucose in the blood); standard 12 lead ECG; heart ultrasound; treadmill test; ECG monitoring by holter; selective coronary angiography (Coronarography);

The data was processed by methods of variational statistics. Continuous variables were displayed as mean and standard deviation, and categorical variables - as count and percentages. Differences in continuous parameters will be analyzed by means of an independent sample $t$-test. The homogeneity of variances will be checked utilizing Levene's analysis. Fisher exact test was used to analyses categorical variables. Selected coronarography results as a reference, the sensitivity, specificity, positive predictive value (PPV), negative predictive value (NPV), and accuracy of silent ishemya were calculated. A 95\% confidence interval was provided by the Wilson score method. Predictors of complications were determined by binary logistic regression analysis. Statistical significance was set at $p<0.05$; The analysis was performed using the program packet SPSS 22.

Results: Our research showed that the median age of participants did not credibly differ in the stenosis group $-47.18 \pm 5.14$ and intact coronary group 46.14 \pm 5.06 . The first table shows frequencies (rates) of possible risk factors in the Stenosis and Intact Groups. 
Table 1: Statistical Assessment of the Predictors of Coronary Stenosis

\begin{tabular}{|c|c|c|c|c|}
\hline & $\begin{array}{l}\text { Any Coronary } \\
\text { Stenosis } n=120\end{array}$ & $\begin{array}{c}\text { Intact Coronaries } \\
\mathrm{n}=65\end{array}$ & & \\
\hline & $\mathrm{n}(\%)$ & $\mathrm{n}(\%)$ & $\mathrm{F}$ & $\mathrm{p}$ \\
\hline Male & $\begin{array}{l}110 \\
(92)\end{array}$ & $49(75)$ & 9.64 & 0.0022 \\
\hline Professional factors - vibration & $\begin{array}{c}70 \\
(58)\end{array}$ & $33(51)$ & 0.97 & 0.3255 \\
\hline Occupational dust & $\begin{array}{c}44 \\
(37)\end{array}$ & 11(17) & 8.13 & 0.0049 \\
\hline Occupational hazards (poisons) & $\begin{array}{c}23 \\
(19)\end{array}$ & $2(3)$ & 9.73 & 0.0021 \\
\hline Stressful job & $\begin{array}{c}69 \\
(58) \\
\end{array}$ & $14(22)$ & 24.75 & $<0.0001$ \\
\hline $\begin{array}{l}\text { Heavy physical load and } \\
\text { professional sport }\end{array}$ & $67(56)$ & $18(28)$ & 14.34 & 0.0002 \\
\hline Unemployed & $56(47)$ & $21(32)$ & 3.61 & 0.0590 \\
\hline $\begin{array}{l}\text { Ischemic disease in } 1^{\text {st }} \text { degree } \\
\text { relatives }\end{array}$ & $55(46)$ & $8(12)$ & 23.56 & $<0.0001$ \\
\hline Hereditary heart diseases & 53(44) & $8(12)$ & 21.39 & $<0.0001$ \\
\hline Smoking & $96(80)$ & $29(45)$ & 27.40 & $<0.0001$ \\
\hline Frequent alcohol consumption & $61(51)$ & $23(35)$ & 4.11 & 0.0442 \\
\hline Urban living area & $53(44)$ & $16(25)$ & 7.08 & 0.0085 \\
\hline Arterial hypertension & $90(75)$ & $23(35)$ & 32.41 & $<0.0001$ \\
\hline Heart failure & $38(32)$ & $5(8)$ & 14.50 & 0.0002 \\
\hline Diabetes Mellitus & $36(30)$ & $2(3)$ & 20.61 & $<0.0001$ \\
\hline Dyslipidemia & $79(66)$ & $25(38)$ & 13.64 & 0.0003 \\
\hline Obesity & $52(43)$ & $2(3)$ & 39.81 & $<0.0001$ \\
\hline Sinus rhythm & $100(83)$ & $62(95)$ & 5.74 & 0.0176 \\
\hline LV moderate or mild dilatation & $104(87)$ & $13(20)$ & 141.31 & $<0.0001$ \\
\hline $\mathrm{EF}^{*}<53.8$ & $86(72)$ & $18(28)$ & 39.91 & $<0.0001$ \\
\hline Atrial Extrasystoles & $38(32)$ & $17(26)$ & 0.61 & 0.4363 \\
\hline Ventricular extrasystoles & $73(61)$ & $23(35)$ & 11.50 & 0.0009 \\
\hline $\mathrm{ST} \downarrow$ or $\mathrm{ST} \uparrow * *$ & $57(48)$ & $10(15)$ & 20.73 & $<0.0001$ \\
\hline Positive treadmill test & $95(79)$ & $11(17)$ & 103.33 & $<0.0001$ \\
\hline Nondiagnostic treadmill test & $25(21)$ & $24(37)$ & 5.72 & 0.0178 \\
\hline Low tolerance to treadmill test & $91(76)$ & $18(28)$ & 51.08 & $<0.0001$ \\
\hline
\end{tabular}

*- ejection fraction

** - ST segment depression (ST $\downarrow$ ) and ST segment alleviation (ST $\uparrow$ )

In the group of any coronary stenosis, the male gender, harmful habits, such as smoking and frequent alcohol consumption, strong physical exertion or professional sport are credibly high. Among those individuals, who have stenosis, rates of following professional factors such as occupational dust, occupational hazards, stressful job, ischemic disease in $1^{\text {st }}$ degree relatives, hereditary heart diseases and urban place of living - city, is credibly high. In 
the group of stenosis, LV moderate dilatation, $\mathrm{EF}<53.8$, the rate of arterial hypertension, cardiac insufficiency (heart failure) and diabetes mellitus, dyslipidemia and obesity, ventricular extrasystoles, ST $\downarrow$ or ST $\uparrow$, the positive treadmill test, low tolerance to treadmill test are credibly high and credibly low - sinus rhythm and nondiagnostic treadmill test.

Dyslipidemia and quantitative data of echocardiography are given in the table 2 .

Table 2: Lipid analysis, coagulation tests and statistical assessment of quantitative data of echocardiography according to the coronary stenosis

\begin{tabular}{|c|c|c|c|c|c|}
\hline & $\begin{array}{c}\text { Any Coronary } \\
\text { Stenosis } n=120\end{array}$ & $\begin{array}{c}\text { Intact Coronaries } \\
\mathrm{n}=65\end{array}$ & Norm & & \\
\hline & Mean+Std. Dev. & Mean+Std. Dev. & & $\mathrm{t}$ & $\mathrm{p}$ \\
\hline $\begin{array}{l}\text { Body mass index } \\
\text { (BMI) }\end{array}$ & $29.69 \pm 3.71$ & $27.02 \pm 2.04$ & $25-30$ & 5.36 & $<0.0001$ \\
\hline Ao $(\mathrm{cm})$ & $3.06 \pm 0.32$ & $2.79 \pm 0.26$ & $2-3.4$ & 5.87 & $<0.0001$ \\
\hline $\begin{array}{l}\text { LV size in } \\
\text { diastole }(\mathrm{cm})\end{array}$ & $6.16 \pm 0.44$ & $5.29 \pm 0.59$ & $\begin{array}{l}3.9-5.3 \\
4.2-5.9\end{array}$ & 11.44 & $<0.0001$ \\
\hline Septum $(\mathrm{cm})$ & $1.25 \pm 0.10$ & $1.17+0.11$ & $0.8-1$ & 5.10 & $<0.0001$ \\
\hline $\begin{array}{l}\text { Ultimate diastole } \\
\text { volume }(\mathrm{ml}) \mathrm{LVd}\end{array}$ & $163.34 \pm 24.95$ & $123.72 \pm 29.40$ & $\begin{array}{l}56-104 \\
67-154 \\
\end{array}$ & 9.67 & $<0.0001$ \\
\hline $\begin{array}{l}\text { LV ultimate } \\
\text { systolic volume } \\
\text { (ml) LV s }\end{array}$ & $81.29 \pm 15.54$ & $54.37 \pm 14.76$ & $\begin{array}{l}19-49 \\
22-58\end{array}$ & 11.63 & $<0.0001$ \\
\hline $\begin{array}{l}\text { Total cholesterol } \\
\text { (TCH) } \mathrm{mm} / \mathrm{l}\end{array}$ & $5.57 \pm 1.00$ & $4.98 \pm 1.14$ & 5.2 & 3.52 & 0.0006 \\
\hline $\begin{array}{l}\text { Triglycerides } \\
\text { (TG) }\end{array}$ & $2.25 \pm 0.72$ & $1.99 \pm 0.57$ & 2.2 & 2.73 & 0.0071 \\
\hline $\begin{array}{l}\text { Low density } \\
\text { lipoprotein } \\
\text { (LDL) }\end{array}$ & $3.49 \pm 0.92$ & $3.10 \pm 1.17$ & 3.4 & 2.46 & 0.0147 \\
\hline $\begin{array}{l}\text { High density } \\
\text { lipoprotein } \\
\text { (HDL) }\end{array}$ & $1.88 \pm 8.76$ & $1.08 \pm 0.20$ & 0.9 & 1.00 & 0.3187 \\
\hline $\begin{array}{l}\text { International } \\
\text { normalized ratio } \\
\text { (INR) }\end{array}$ & $1.01 \pm 0.08$ & $1.03 \pm 0.08$ & $0.83-1.51$ & -1.63 & 0.1061 \\
\hline $\begin{array}{l}\text { Prothrombin } \\
\text { index }\end{array}$ & $100.30 \pm 14.68$ & $97.62 \pm 13.43$ & $70-110$ & 1.25 & 0.2120 \\
\hline $\begin{array}{l}\text { Fibrinogen } \\
\text { concentration }\end{array}$ & $461.38 \pm 108.05$ & $476.86 \pm 113.32$ & $200-400$ & -0.90 & 0.3693 \\
\hline $\mathrm{EF} \%$ & $\begin{array}{r}49.74 \\
+5.80 \\
\end{array}$ & $55.60 \pm 5.07$ & $53.8-66.2$ & -6.85 & $<0.0001$ \\
\hline
\end{tabular}

Among those persons, who had stenosis, the following echocardiography data, such as Ao $(\mathrm{cm}), \mathrm{LV}$ size in diastole $(\mathrm{cm})$, septum (cm), LVultimate diastolic volume ( $\mathrm{ml}) \mathrm{LVd}$, and LV ultimate systolic volume 
(ml) were credibly high. These are characteristic features of the moderate dilatation of the left ventricle.

In the stenosis group, with intact patients, the ejection fraction was relatively and credibly low.

Out of the lipid exchange, TCH, TG, and LDL are convincingly increased.

At the next step of the research, we performed the correlational analysis between the stenosis and predictors of silent ischemia (Table 3).

Table 3: Correlation between Stenosis and Silent Ischemia Predictors

\begin{tabular}{|l|c|}
\hline \multirow{2}{*}{ Predictors } & Any Coronary Stenosis \\
\cline { 2 - 2 } & $\mathrm{r}$ \\
\hline LV moderate dilatation & $0.660^{* *}$ \\
\hline Dyslipidemia & $0.263^{* *}$ \\
\hline EF<53.8 & $0.423^{* *}$ \\
\hline Obesity & $0.423^{* *}$ \\
\hline Atrial extrasystoles & 0.058 \\
\hline Ventricular extrasystoles & $0.243^{* *}$ \\
\hline & \\
ST segment depression (ST $\downarrow)$ and ST segment & $0.319^{* *}$ \\
alleviation (ST $\uparrow)$ & \\
\hline Positive treadmill test & $0.601^{* *}$ \\
\hline Nondiagnostic treadmill test & $-0.174^{*}$ \\
\hline Low tolerance to treadmill test & 0.047 \\
\hline Sinus rhythm & $-0.174^{*}$ \\
\hline Arterial hypertension & $0.388^{* *}$ \\
\hline Cardiac insufficiency & $0.271^{* *}$ \\
\hline Professional factors - vibration & 0.073 \\
\hline Occupationaldust & $0.206^{* *}$ \\
\hline Occupationalhazards & $0.225^{* *}$ \\
\hline Stressful job & $0.345^{* *}$ \\
\hline Heavy physical load or professional sport & $0.270^{* *}$ \\
\hline Unemployment & 0.139 \\
\hline Ischemic disease among 1st degree relatives & $0.338^{* *}$ \\
\hline $\begin{array}{l}\text { Hereditary heart diseases among } 1^{\text {st }} \text { degree } \\
\text { relatives }\end{array}$ & $0.324^{* *}$ \\
\hline Frequent alcohol consumption & $0.148^{*}$ \\
\hline Urban living area - city & $0.193^{* *}$ \\
\hline Diabetes Mellitus & $0.318^{* *}$ \\
\hline Smoking & $0.361^{* *}$ \\
\hline Male gender & $0.224^{* *}$ \\
\hline & \\
& \\
\hline & \\
\hline
\end{tabular}

Any coronary stenosis by more than $50 \%-\mathrm{r}=0.531 ; \mathrm{p}=0.000$ and 30 to $50 \%$ Stenosis $-\mathrm{r}=0.531 ; \mathrm{p}=0.000$, shows convincing positive correlation with LV moderate (mild) dilatation. 
Dyslipidemia, $\mathrm{EF}<53.8 \mathrm{p}=0.000$, obesity, ventricular extrasystoles, $\mathrm{ST}$ $\downarrow$ or ST $\uparrow$, positive treadmill test, low tolerance treadmill test, arterial hypertension, cardiac insufficiency (heart failure), occupational dust, occupational hazards, stressful job, heavy physical load, or professional sport; Ischemic disease in $1^{\text {st }}$ degree relatives, hereditary heart diseases, frequent alcohol consumption, urban living place, diabetes mellitus, smoking, male gender show credibly positive correlation with coronary artery stenosis. The negative correlation is shown by the nondiagnostic treadmill test and the sinus rhythm;

On the basis of correlational analyses, we performed the regressive analyses, as the result of which, we received the coronary stenosis risk assessment according to the initial characteristics (table 4).

Table 4: Coronary Stenosis Risk Assessment in Patients with Silent Ischemia

\begin{tabular}{|l|c|c|c|c|c|c|c|}
\hline & B & S.E. & Wald & $p$ & $\operatorname{Exp}(\mathrm{B})$ & \multicolumn{2}{|c|}{$\begin{array}{c}\text { 95\% C.I.for } \\
\text { EXP(B) }\end{array}$} \\
\cline { 1 - 4 } & & & & & & Lower & Upper \\
\hline Smoking & 2.02 & 0.75 & 7.30 & 0.0069 & 7.57 & 1.74 & 32.86 \\
\hline Sinus rhythm & -7.10 & 1.81 & 15.35 & 0.0001 & 0.00 & 0.00 & 0.03 \\
\hline $\begin{array}{l}\text { Positive treadmill } \\
\text { test }\end{array}$ & 2.86 & 0.85 & 11.32 & 0.0008 & 17.45 & 3.30 & 92.27 \\
\hline $\begin{array}{l}\text { LV moderate } \\
\text { dilatation }\end{array}$ & 4.57 & 1.00 & 20.77 & $<0.0001$ & 97.01 & 13.56 & 693.89 \\
\hline Male gender & 2.00 & 0.95 & 4.46 & 0.0347 & 7.38 & 1.15 & 47.15 \\
\hline Dyslipidemia & 2.66 & 0.88 & 9.09 & 0.0026 & 14.36 & 2.54 & 81.10 \\
\hline $\begin{array}{l}\text { Ischemic disease in } \\
1^{\text {st }} \text { degree relatives }\end{array}$ & 1.64 & 0.84 & 3.86 & 0.0493 & 5.17 & 1.00 & 26.63 \\
\hline $\begin{array}{l}\text { Arterial } \\
\text { hypertension }\end{array}$ & 2.35 & 0.81 & 8.43 & 0.0037 & 10.49 & 2.15 & 51.28 \\
\hline $\begin{array}{l}\text { Low tolerance to } \\
\text { treadmill test }\end{array}$ & 1.90 & 0.81 & 5.51 & 0.0189 & 6.72 & 1.37 & 32.93 \\
\hline Constant & -9.07 & 1.81 & 25.14 & $<0.0001$ & 0.00 & & \\
\hline & & & & & & & \\
\hline
\end{tabular}
table 5 .

The assessment of moderate dilatation as the diagnostic test is given in

Table5: Assessment of diagnostic test

\begin{tabular}{|c|c|c|c|c|}
\hline Results & True positive & False positive & $\begin{array}{c}\text { False } \\
\text { negative }\end{array}$ & True negative \\
\hline Abs. & 104 & 13 & 16 & 52 \\
\hline$\%$ & 56.22 & 7.02 & 8.65 & 28.11 \\
\hline
\end{tabular}

As it is seen from the schedule, in the data, true positive and true negative results prevail. The number of false results is low. 
These results allowed us to assess the prognostic value and the diagnostic accuracy of moderate dilatation as the diagnostic test of Ischemia (table 6).

Table 6: Prognostic value and diagnostic accuracy of LV moderate dilatation

\begin{tabular}{|c|c|c|c|c|c|}
\hline & Sensitivity & Specificity & $\begin{array}{c}\text { Prognostic } \\
\text { value of } \\
\text { positive } \\
\text { results }\end{array}$ & $\begin{array}{c}\text { Prognostic } \\
\text { value of } \\
\text { negative } \\
\text { results }\end{array}$ & $\begin{array}{c}\text { Diagnostic } \\
\text { value }\end{array}$ \\
\hline $\begin{array}{c}\text { Test } \\
\text { assessment }\end{array}$ & 0.867 & 0.800 & 0.889 & 0.765 & 0.843 \\
\hline \multirow{2}{*}{$95 \%$ CI } & 0.806 & 0.703 & 0.832 & 0.664 & 0.791 \\
\cline { 2 - 6 } & 0.927 & 0.897 & 0.946 & 0.866 & 0.896 \\
\hline
\end{tabular}

The data show that test specificity and sensitivity are rather high which defines high prognostic value and diagnostic accuracy. Thus, the LV moderate dilatation of the left ventricle can be used for primary diagnosing of silent ischemia.

\section{Discussion}

According to the literature, High blood pressure is the geometry of the heart chambers One of the important factors of remodeling [Huang, G., 2009]. According to the new paradigm of the disease, patients with hypertension are prone to abnormal myocardial remodeling[díez j.2009], modeling is complex in its structure and function change and involves an increase in myocardial mass, geometric character change, and camera dilatation [Talibov AH, 2013]. As this study has shown, hypertension is a risk factor for stenosis The development of coronary heart disease is related to sex [Gujejaini L, et al. 2015]. According to this data, males show a positive correlation with stenosis with silent ischemia.

Obesity is associated with greater LV remodeling in established cardiac disease than in the normal heart, with obesity-related LV dilatation increasing 3-fold [Rayner, J. J, et al. 2020], Which is confirmed by this study

Left ventricular sports remodeling develops In response to prolonged and high-intensity physical exertion, According to the traditional view, it is adaptive in nature and at this time The changes developed do not go beyond the physiological limits. However, Arguments in favor of different views are obtained [Ivanova Yu.M.,2020]. According to this study, heavy physical load or professional sport and LV moderate dilatation correlated with any coronary stenosis.

That test specificity and sensitivity are rather high which define high prognostic value and diagnostic accuracy. 


\section{Conclusion}

In patients with silent ischemia, the coronary disease predictors are: left ventricular moderate dilatation, male gender, dyslipidemia, arterial hypertension, smoking, positive treadmill test, ischemic disease in $1^{\text {st }}$ degree relatives, low tolerance to a treadmill test.

Thus, we can use the moderate dilatation of the left ventricle for the primary diagnosis of silent ischemia.

The test is simple and non-invasive. It is characterized by high sensitivity and specificity and can be used for early diagnosis of silent ischemia and the prevention of cardiac cases.

\section{References:}

1. Abd El-Aziz, T. A., Hussein, Y. M., Elsebaie, M. H., Mohammad, H. A., \& Mohamed, R. H. (2015). A new metabolic mechanism for absence of pain in patients with silent myocardial ischemia. Archives of medical research, 46(2), 127-132.

2. Conti, C. R., Bavry, A. A., \& Petersen, J. W. (2012). Silent ischemia: clinical relevance. Journal of the American College of Cardiology, 59(5), 435-441.

3. Díez J. (2013). Hypertension. Hypertensive heart disease. (6) 152-166

4. Díez, J. (2009). Towards a new paradigm about hypertensive heart disease. Medical Clinics of North America, 93(3), 637-645.

5. Gigli, M., Stolfo, D., Merlo, M., Barbati, G., Ramani, F., Brun, F., ... \&Sinagra, G. (2017). Insights into mildly dilated cardiomyopathy: temporal evolution and long-term prognosis. European journal of heart failure, 19(4), 531-539.

6. Guerra F, Mancinelli L, Angelini L, et al. The Association of Left Ventricular Hypertrophy with Metabolic Syndrome is Dependent on Body Mass Index in Hypertensive Overweight or Obese Patients. PLoS One. 2011; 6 (1): e16630.

7. Gujejaini L. Sharashidze N. Pagava Z. Mamatsahvili M. Aladashvili L. Taboridze I. Saatashvili G. Gender related differences in outcomes following percutaneous coronary interventions in different age groups of patients with st-elevation acute myocardial infarction. European Scientific Journal February 2015 edition vol.11, No.6

8. Gutermann De silent Myocardial Ischemia. (2009). Circ J; 73, 785 79

9. Hansson, G. K., Hamsten, A., Goldman, L., \& Schafer, A. I. (2016). Atherosclerosis, thrombosis, and vascular biology. Goldman-Cecil Medicine. 25th ed. Philadelphia, PA: Elsevier Saunders. 
10. Huang, G., Gao, H., Meng, X., Yan, Z., Kong, X., \& Wang, L. (2009). Related factors of dilated cardiomyopathy. Journal of Geriatric Cardiology, 6(2), 87-90.

11. Ivanova Yu.M., Pavlov V.I., Badtieva V.A., Ordzhonikidze Z.G., \& Sharykin A.S. (2020). Dilation of the left ventricle in athletes. Russian Journal of Cardiology, (S2), 31-32.

12. Laslett, L. J., Alagona, P., Clark, B. A., Drozda, J. P., Saldivar, F., Wilson, S. R., ... \& Hart, M. (2012). The worldwide environment of cardiovascular disease: prevalence, diagnosis, therapy, and policy issues: a report from the American College of Cardiology. Journal of the American College of Cardiology, 60(25), 1-49.

13. Mendis, S., Puska, P., Norrving, B., \& World Health Organization. (2011). Global atlas on cardiovascular disease prevention and control. World Health Organization.

14. Narayanan, K., Reinier, K., Teodorescu, C., Uy-Evanado, A., Aleong, R., Chugh, H., ... \&Chugh, S. S. (2014). Left ventricular diameter and risk stratification for sudden cardiac death. Journal of the American Heart Association, 3(5), e001193.

15. Rayner, J. J., Abdesselam, I., d'Arcy, J., Myerson, S. G., Neubauer, S., Watkins, H., ... \& Rider, O. J. (2020). Obesity-related ventricular remodelling is exacerbated in dilated and hypertrophic cardiomyopathy. Cardiovascular Diagnosis and Therapy, 10(3), 559.

16. Talibov AH,. (2013). Dependence of echocardiographic indicators on the age and duration of the sport. Learned records of their university. PF Lesgafta, (8 (102)). 